OPEN ACCESS

Edited by: Malcolm Xing,

University of Manitoba, Canada

Reviewed by: Ahmed El-Fiqi,

Dankook University, South Korea Xiaozhong Qiu,

Southern Medical University, China

*Correspondence: Ennio Tasciotti etasciotti@houstonmethodist.org

Specialty section: This article was submitted to Biomaterials,

a section of the journal Frontiers in Bioengineering and Biotechnology

Received: 29 March 2016 Accepted: 20 May 2016 Published: 02 June 2016

Citation:

Minardi S, Taraballi F, Pandolfi L and Tasciotti E (2016) Patterning Biomaterials for the Spatiotemporal Delivery of Bioactive Molecules. Front. Bioeng. Biotechnol. 4:45. doi: 10.3389/fbioe.2016.00045

\section{Patterning Biomaterials for the Spatiotemporal Delivery of Bioactive Molecules}

\author{
Silvia Minardi' ${ }^{1}$ Francesca Taraballi', Laura Pandolfi ${ }^{1,2}$ and Ennio Tasciotti ${ }^{1,3 *}$ \\ ${ }^{1}$ Department of Regenerative Medicine, Houston Methodist Research Institute, Houston, TX, USA, ${ }^{2}$ College of Materials \\ Science and Engineering, University of Chinese Academy of Science, Beijing, China, ${ }^{3}$ Department of Orthopedics, Houston \\ Methodist Hospital, Houston, TX, USA
}

The aim of tissue engineering is to promote the repair of functional tissues. For decades, the combined use of biomaterials, growth factors (GFs), and stem cells has been the base of several regeneration strategies. Among these, biomimicry emerged as a robust strategy to efficiently address this clinical challenge. Biomimetic materials, able to recapitulate the composition and architecture of the extracellular matrix, are the materials of choice, for their biocompatibility and higher rate of efficacy. In addition, it has become increasingly clear that restoring the complex biochemical environment of the target tissue is crucial for its regeneration. Toward this aim, the combination of scaffolds and GFs is required. The advent of nanotechnology significantly impacted the field of tissue engineering by providing new ways to reproduce the complex spatial and temporal biochemical patterns of tissues. This review will present the most recent approaches to finely control the spatiotemporal release of bioactive molecules for various tissue engineering applications.

Keywords: biomaterials, patterning, tissue engineering, growth factors, drug delivery

\section{INTRODUCTION}

The use of autologous or heterologous cells in clinical practice has always been considered the most advantageous strategy for boosting tissue repair (Jaklenec et al., 2012). However, several downsides, such as their costs, availability, risk of infection, pain, and low viability after injection, subvert their advantages (Harrison et al., 2014). Thus, the ability to elicit specific cell responses in vivo through the release of bioactive signaling molecules has attracted increasing attention.

Growth factors (GFs) are soluble molecules that control a wide range of signaling pathways by binding to specific cell receptors (Vo et al., 2012). In 2010, therapeutics based on bioactive proteins and peptides represented about 13\% of global sales in the biomedical field (Sheridan, 2010). Furthermore, sales have been predicted to increase from $\$ 14.1$ billion in 2011 to $\$ 25.4$ billion by 2018 (Fosgerau and Hoffmann, 2015).

The biological response triggered by a GF depends on the target cells, their number, and other signaling factors present in the milieu of a specific tissue. Therefore, the successful use of GFs in regenerative therapies requires the selection of appropriate GFs to accomplish optimal tissue repair. Toward this end, the precise regulation of GFs' concentration in space and time is vital (Guldberg, 2009).

In order to increase functional regeneration, many proposed approaches combine surgical procedures, biologics, and biomaterials (Fisher and Mauck, 2013). Biomaterials (derived from natural or synthetic sources) are contributing to groundbreaking work in many tissue 
engineering applications (Balint et al., 2014), including bone and cartilage regeneration (Tampieri et al., 2008; Henkel et al., 2013; Minardi et al., 2015). The biomaterials market for implantable devices is estimated to be worth $\$ 33$ billion by the end of 2019 (Transparency Market Research, 2012). Tissue healing in musculoskeletal surgery has benefited from the surgical implantation of bio-conductive scaffolds (Hsu et al., 2012). However, the use of GFs and chemo/cytokines in clinical practice yielded controversial results (Garner et al., 2011; Anitua et al., 2012). One famous example involved the use of recombinant human bone morphogenetic protein-2 (rhBMP-2) in spinal fusion (Medtronic, INFUSE ${ }^{\circledR}$ : rhBMP-2-infused collagen scaffold). Although approved by the US Food and Drug Administration (FDA) in 2002, the high doses of rhBMP-2 used by this device resulted in major adverse side effects, including cancer, spinal cord compression from soft tissue swelling, spinal cord impingement from ectopic bone formation, elevated bone resorption from osteoclast activation, and preferential induction of adipogenesis over osteogenesis (Kaneko et al., 2000; Smucker et al., 2006; Wong et al., 2008; Robin et al., 2010; Zara et al., 2011; Epstein, 2013).

These side effects were caused by the massive release of rhBMP-2 from the collagen sponge after implantation (5-10 mg of BMP-2/implant) (McKay et al., 2007). This dose is over 5000 times higher than the amount required for bone formation in vitro (Wang et al., 1988; Place et al., 2009) and even higher than physiologic doses found in the osteogenic niche where other osteogenic stimuli (chemical, physical, and structural) additionally contribute to induce bone formation (Place et al., 2009; Tampieri et al., 2011). When the uncontrolled pharmacokinetics showed adverse side effects, the FDA revoked the device's approval (McKie et al., 2014).

After this, GF dose-response effects became all the more crucial (Shields et al., 2006), and it became evident that adverse outcomes could have been avoided with the controlled, localized release of rhBMP-2. It was determined that burst release and widespread tissue exposure to GFs, together with an early dissipation from the implantation site (e.g., with irrigation, bleeding, and edema) were not ideal pharmacokinetics for tissue regeneration (Lai et al., 2013). Furthermore, it has become clear that the first-order release of a single bioactive molecule is not sufficient to mimic the complex biochemical gradients present at a specific stage of tissue regeneration (Wang et al., 2013; Minardi et al., 2014).

Extraordinary progress has been made toward the design of biomaterials with suitable multiscale hierarchical structures, facilitating the staged release of a combination of bioactive molecules, according to any complex delivery pattern (Biondi et al., 2008; Guldberg, 2009; Chen et al., 2010).

Bioactive factors can be incorporated within materials using layer deposition or integrated into their fibrous mesh via electrospinning or self-assembly techniques (Sun et al., 2003; Hosseinkhani et al., 2006; Minardi et al., 2014). Herein, we review the most recent strategies for biomaterial fabrication, featuring spatiotemporal patterns of bioactive molecules.

\section{ENGINEERING 3D BIOPATTERNED MATERIALS}

The three-dimensional (3D) interactions between cells and the extracellular matrix (ECM) have been proven to be crucial to orchestrate tissue formation and regeneration in response to injury. Materials such as hydrogels and scaffolds engineered to emulate the ECM can support tissue healing (Hoffman, 2012; Loh and Choong, 2013).

Three-dimensional patterning has been defined as the entrapment of biochemical (Lee et al., 2015a) or structural heterogeneity (Zorlutuna et al., 2011) within the structure of a material and successfully employed in the design of biomimetic materials for tissue engineering. To emulate tissues' biochemical gradients, the patterning of bioactive molecules within biomaterials should be controlled over time and space (Figure 1).
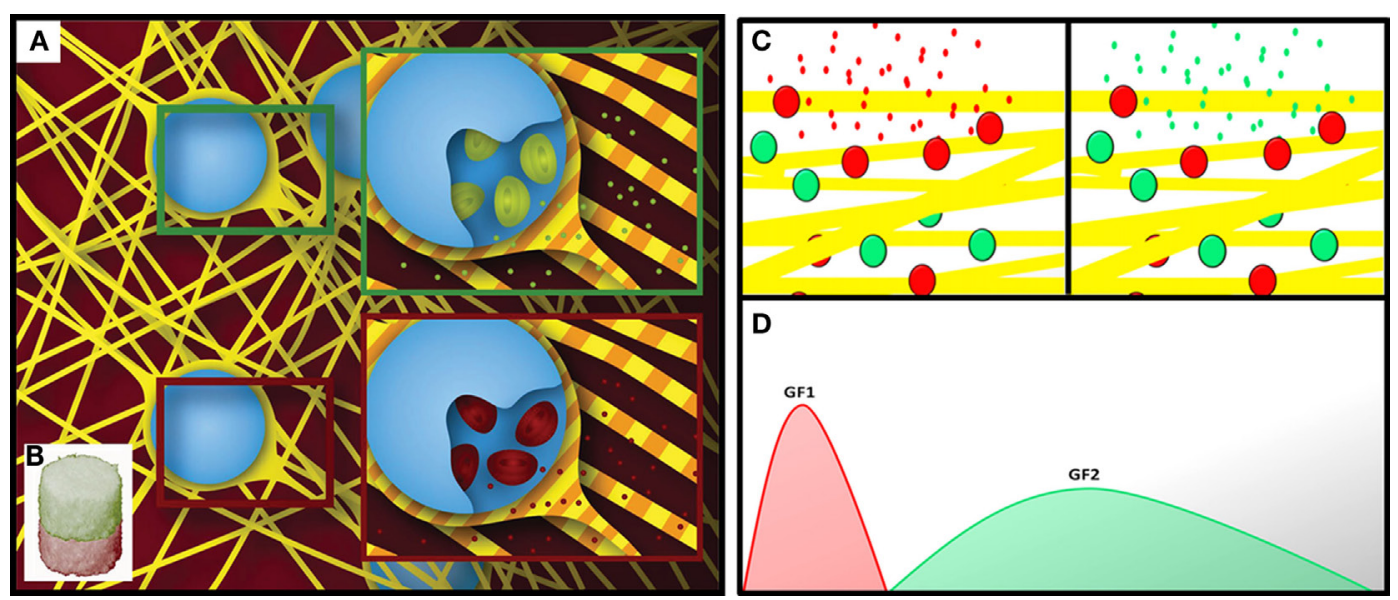

FIGURE 1 | Schematic showing a spatially patterned fibrous material functionalized with different sets of delivery systems (A), in separate compartments (B) (Minardi et al., 2014). Schematic showing the temporal patterning of a material with two sets of delivery systems (C), for the staged release of bioactive molecules (D). 
This has been accomplished using multiple strategies that facilitate controlled spatial and temporal release kinetics.

Hydrogels capable of promoting cell viability and interactions with elements of the ECM have been advantageous for many regenerative medicine applications (Nguyen and West, 2002). Hydrogels are highly hygroscopic polymers that can be fully engineered to mimic specific chemical and physical properties of tissues and are therefore often used as scaffolding materials for tissue engineering applications (Tibbitt and Anseth, 2009). Additionally, due to their biocompatibility and ability to control the release rates of bioactive molecules, hydrogels have been successfully used as drug reservoirs in tissue engineering applications (Peppas et al., 2006). The 3D patterning of hydrogels is crucial to enhance their spatial heterogeneity and improve their features for cell seeding. 3D patterning can fall into two categories: those that integrate patterning during fabrication (i.e., stereolithography) or those that involve post-processing of a uniform hydrogel (Ahmed, 2015). Horn et al. (2007) created hydrogels suitable for spinal cord repair by combining thiol-modified hydroxyl-apatite with acrylate-functionalized poly(ethylene glycol) (PEG). Tsang et al. (2007) developed a multilayer PEG hexagonal hydrogel functionalized with hepatocyte cells and demonstrated better cell viability in the center of the construct compared to uniform hydrogel disks. Lim and Sun (1980) used alginate-based polymers cross-linked with calcium ions for the treatment of diabetic animals. De Souza et al. (2009) demonstrated the in vivo biocompatibility of chitosan, phospholipids, and lauric aldehyde or lauric chloride hydrogel blends. Hydrogels can also be patterned by indirect binding. In an elegant recent study, Stupp and coworkers described a successful example of this strategy: they proposed peptide amphiphile nanofibers gels with binding affinity for BMP-2 (Rajangam et al., 2008; Lee et al., 2015b), to solve the health concerns associated with the use of this factor in patients. Others have successfully functionalized the surface of gels and scaffolds with heparin or others glycosaminoglycans to dock bioactive molecules in situ (Liang and Kiick, 2014; Corradetti et al., 2016).

One of the major concerns in the engineering of materials functionalized with bioactive molecules for regenerative medicine is the preservation of the payload (Minardi et al., 2016). Due to their structure, 3D scaffolds proved successful in minimizing bioactive factors' exposure to harsh conditions in vivo, preserving their bioactivity (Yuan and Liu, 2012).

Scaffolds have been biochemically patterned through many different approaches. An established strategy consists of the integration of microparticles into the biomaterial structure (Chen et al., 2010). Integrating delivery systems within the scaffold matrix enables the design of scaffolds with patterns of various geometries and purpose, while controlling their release (LópezNoriega et al., 2015).

Similarly, our group proposed a chitosan-gelatin scaffold functionalized with composite microspheres consisting of mesoporous silicon microparticles and poly(lactic-co-glycolic acid) (PLGA) for the controlled release of small bioactive molecules (Pandolfi et al., 2016). Wei et al. (2007) showed that incorporating PLGA nanospheres into nanofibrous poly(L-lactic acid) (PLLA) scaffolds loaded with rhBMP-7 enhanced osteogenesis. Kim et al. (2004) accomplished the incorporation of a combination of drugs into a PLGA-based fibrous mat, fabricated through electrospinning.

Interface tissue engineering focuses on the development of tissue grafts capable of replacing defective interfaces, such as ligament-to-bone, tendon-to-bone, and cartilage-to-bone (Almodóvar et al., 2014). These interfaces exhibit anisotropic structural properties, which gradually vary from one tissue to another. Using homogeneous biomaterials ultimately leads to graft failures (Seidi et al., 2011). Singh et al. (2008) introduced an interesting microparticle-based scaffold fabrication technique as a method to create 3D scaffolds with spatial control over multiple bioactive molecules using uniform PLGA microspheres. They demonstrated that embedding the PLGA microparticles into their scaffolds led to more sustained payload release. Recently, we proposed a multiscale approach to selectively integrate different types of nanostructured composite microspheres in a multicompartmented collagen scaffold (Minardi et al., 2014). By fully embedding the microspheres in the type I collagen matrix of the scaffold, the authors were able to spatially pattern the microspheres into the different compartments, and the collagen coating on the microspheres allowed for the zero-order release of the payload for almost 2 months. This method of scaffold functionalization proved to preserve the bioactivity of cytokines for several weeks. The controlled release of the payloads over long periods of time favors on-scaffold cell recruitment while avoiding adverse effects due to the bolus administration of therapeutic molecules in the tissues surrounding the implant (Minardi et al., 2016). To achieve the combined release of multiple molecules from different compartments, Song et al. (2012) incorporated silica nanoparticles into electrospun fibers. Detamore's group attempted osteochondral regeneration through the creation of continuous gradients of two bioactive factors within a 3D scaffold (Dormer et al., 2010). The authors developed a polymer microsphere-based scaffold, which could be fabricated using microspheres loaded with various GFs to create continuous and opposite gradients of BMP-2 and transforming growth factorbeta (TGF- $\beta$ ) (Mohan et al., 2011).

\section{CELL RESPONSE TO 3D BIOCHEMICALLY PATTERNED MATERIALS}

Most of the current understanding of the regenerative process is based on the use of simplified in vitro $2 \mathrm{D}$ cell cultures, which fail to reproduce tissue complexity. Recently, 3D cultures on biomimetic materials mimicking the ECM microenvironment are becoming the in vitro models of choice to study the regenerative process of specific tissues. $3 \mathrm{D}$ biomimetic cultures are more physiologically relevant than those in $2 \mathrm{D}$ and simpler than in vivo models (Hoffmann and West, 2010). As reviewed in the previous paragraph, over the past decade various technologies have been developed to create spatiotemporal gradients for complex biomaterials (Santos et al., 2012). Graded materials can elicit various cell behaviors, such as adhesion, orientation, motility, surface antigen display, cytoskeletal condensation, activation of tyrosine 


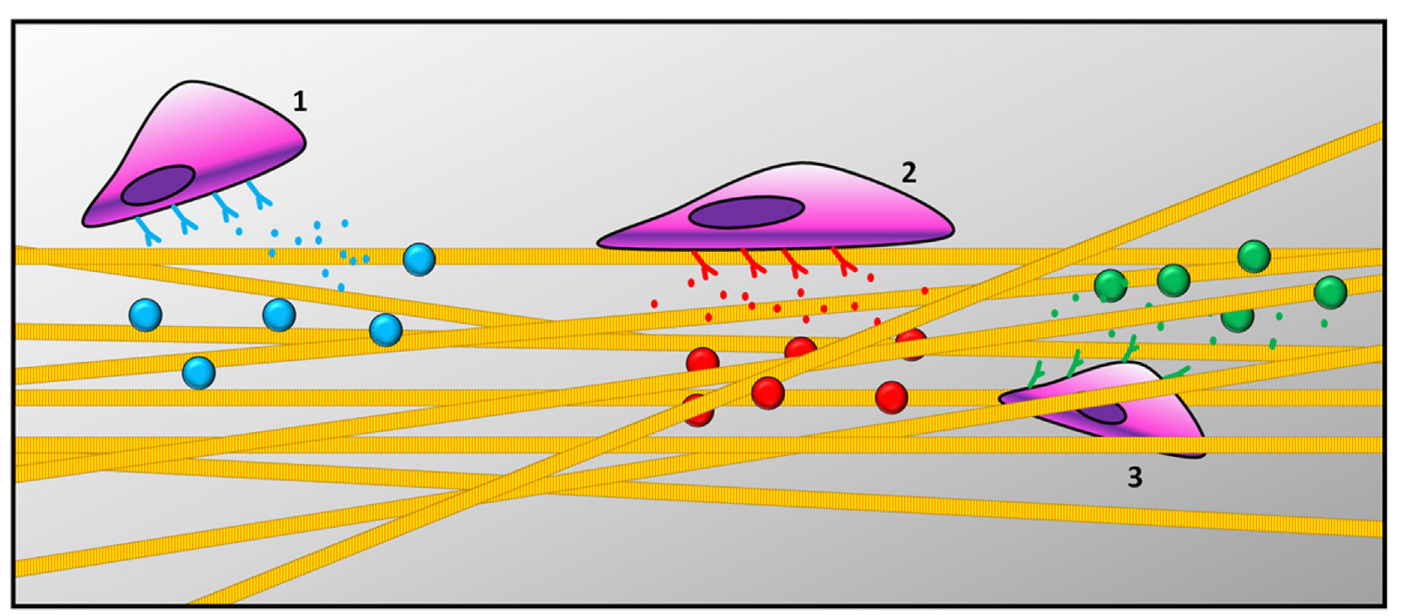

FIGURE 2 | Schematic representation of cells responding to gradient patterns: (1) cells recruitment, (2) cell adhesion on the surface of the scaffold, and (3) cell migration across scaffold thickness.

kinases, and modulation of intracellular signaling pathways that regulate transcriptional activity and gene expression (Figure 2). Cells are able to decode information provided by the ECM and respond to specific stimuli, such as topography (Ishii et al., 2005; Raghunathan et al., 2013), mechanical properties (Ulrich et al., 2009; Humphrey et al., 2014), bioactive signals (Li and Folch, 2005; Yañez-Soto et al., 2013; Malik et al., 2015), and concentration gradients of both soluble and tethered GFs (Gattazzo et al., 2014). An established strategy to elicit such biological functions consists of the functionalization of hydrogels with biochemical cues, as described above (Tibbitt and Anseth, 2009; Geckil et al., 2010). Synthetic biomaterials, such as hydrogels or bulk polymeric scaffolds, demonstrated low cellular adhesion, necessitating functionalization with bioactive molecules (Tian et al., 2012). Since synthetic hydrogels lack biochemical cues, different strategies for their 3D biochemical patterning have been developed to increase their level of biomimicry (Luo and Shoichet, 2004) and enhance their interaction with cells (Yan et al., 2011). To favor cell adhesion, migration, and differentiation within hydrogels, the main strategy has been to immobilize adhesive peptides (e.g., RGD) (Bellis, 2011). The use of short peptides to tune cellular response to hydrogels showed success due to the stability of the chemical conjugation between the peptide of interest and the material, without altering its conformation.

Recently, in a very elegant study, the Anseth research group proposed an RGD patterned hydrogel, synthesized through a versatile process of sequential bio-orthogonal click-chemistry reactions (DeForest et al., 2009). Their approach was further developed by García and coworkers, who proposed light to trigger adhesive peptides on the surface of their hydrogel in vivo (Lee et al., 2015c). Adhesion and proliferation are not the only two important features to achieve tissue homeostasis, but also cell migration is fundamental for all morphogenetic processes in tissue regeneration (Sternlicht and Werb, 2001). Cell migration occurs in response to gradients of soluble or insoluble signals. In tridimensional constructs, migration is more difficult to achieve due to the mechanical resistance of the surrounding ECM. Synthetic materials must contain cell-adhesive ligands for traction, GFs as signals of migration, as well as space to allow cell movement. Taraballi and colleagues synthesized a plethora of different hydrogels functionalized with bioactive peptides (BMPH1 andBMPH2) that allowed for the adhesion, proliferation, and differentiation of neural stem cells into neurons both in vitro and in vivo (Gelain et al., 2010, 2011; Taraballi et al., 2010). They demonstrated that neural cells were able to migrate inside the gel but only extended neurites when both factors were presented at the same time. Their findings suggested that several signaling molecules could work best in combination, benefiting from their synergistic effect.

However, in the natural ECM, cells not only respond to signals presented on the surface of the ECM but also to soluble stimuli, especially in the regeneration process. Usually, these factors diffuse through the ECM and bind to their specific receptors on cells' surface, activating specific transduction cascades. In vivo, the transient nature of GF signaling is combined with the slow, sustained signals received from the ECM (Lund et al., 2009). For example, epidermal growth factor (EGF), FGFs, TGF- $\beta$, and platelet-derived growth factor (PDGF) (Farokhi et al., 2013) have been used to accelerate wound healing by inducing both epithelial cell and fibroblast proliferation, as well as de novo matrix deposition (Kim et al., 2012). Similarly, the release of insulin-like growth factor 1 (IGF-1) and TGF- $\beta 1$ from polymer scaffolds functionalized with delivery systems showed to successfully induce chondrogenic differentiation (Ertan et al., 2013).

\section{CONCLUSION}

In the past decade, significant advances have been accomplished in the design of biopatterned materials able to accomplish temporally and/or spatially controlled release of bioactive molecules. Despite these advances, methods should be further developed to prepare patterns and gradients with controlled shape and 
kinetics, in order to tune the desired cell mechanisms in vivo. Altogether, the studies herein reviewed show the potential of $3 \mathrm{D}$ biomaterials spatiotemporally patterned with bioactive molecules to recapitulate the complex biochemical milieu of target tissues.

\section{AUTHOR CONTRIBUTIONS}

SM and FT conceived the idea of this review. SM wrote the Abstract, Introduction, and Conclusion sections. LP drafted the first paragraph, FT drafted the second paragraph, and SM and FT revised and finalized the mini-review with the help of ET.

\section{REFERENCES}

Ahmed, E. M. (2015). Hydrogel: preparation, characterization, and applications: A review. J. Adv. Res. 6, 105-121. doi:10.1016/j.jare.2013.07.006

Almodóvar, J., Guillot, R., Monge, C., Vollaire, J., Selimović, Š., Coll, J.-L., et al. (2014). Spatial patterning of BMP-2 and BMP-7 on biopolymeric films and the guidance of muscle cell fate. Biomaterials 35, 3975-3985. doi:10.1016/j. biomaterials.2014.01.012

Anitua, E., Alkhraisat, M. H., and Orive, G. (2012). Perspectives and challenges in regenerative medicine using plasma rich in growth factors. J. Control. Release 157, 29-38. doi:10.1016/j.jconrel.2011.07.004

Balint, R., Cassidy, N. J., and Cartmell, S. H. (2014). Conductive polymers: towards a smart biomaterial for tissue engineering. Acta Biomater. 10, 2341-2353. doi:10.1016/j.actbio.2014.02.015

Bellis, S. L. (2011). Advantages of RGD peptides for directing cell association with biomaterials. Biomaterials 32, 4205-4210. doi:10.1016/j.biomaterials. 2011.02.029

Biondi, M., Ungaro, F., Quaglia, F., and Netti, P. A. (2008). Controlled drug delivery in tissue engineering. Adv. Drug Deliv. Rev. 60, 229-242. doi:10.1016/j. addr.2007.08.038

Chen, F.-M., Zhang, M., and Wu, Z.-F. (2010). Toward delivery of multiple growth factors in tissue engineering. Biomaterials 31, 6279-6308. doi:10.1016/j. biomaterials.2010.04.053

Corradetti, B., Taraballi, F., Minardi, S., Van Eps, J., Cabrera, F., Francis, L. W., et al. (2016). Chondroitin sulfate immobilized on a biomimetic scaffold modulates inflammation while driving chondrogenesis. Stem Cells Transl. Med. 5, 670-682. doi:10.5966/sctm.2015-0233

De Souza, R., Zahedi, P., Allen, C. J., and Piquette-Miller, M. (2009). Biocompatibility of injectable chitosan-phospholipid implant systems. Biomaterials 30, 3818-3824. doi:10.1016/j.biomaterials.2009.04.003

DeForest, C. A., Polizzotti, B. D., and Anseth, K. S. (2009). Sequential click reactions for synthesizing and patterning three-dimensional cell microenvironments. Nat. Mater. 8, 659-664. doi:10.1038/nmat2473

Dormer, N. H., Singh, M., Wang, L., Berkland, C. J., and Detamore, M. S. (2010). Osteochondral interface tissue engineering using macroscopic gradients of bioactive signals. Ann. Biomed. Eng. 38, 2167-2182. doi:10.1007/ s10439-010-0028-0

Epstein, N. E. (2013). Complications due to the use of BMP/INFUSE in spine surgery: the evidence continues to mount. Surg. Neurol. Int. 4, S343-S352. doi:10.4103/2152-7806.114813

Ertan, A. B., Yılgor, P., Bayyurt, B., Çalıkoğlu, A. C., Kaspar, Ç., Kök, F. N., et al. (2013). Effect of double growth factor release on cartilage tissue engineering. J. Tissue Eng. Regen. Med. 7, 149-160. doi:10.1002/term.509

Farokhi, M., Mottaghitalab, F., Ai, J., and Shokrgozar, M. A. (2013). Sustained release of platelet-derived growth factor and vascular endothelial growth factor from silk/calcium phosphate/PLGA based nanocomposite scaffold. Int. J. Pharm. 454, 216-225. doi:10.1016/j.ijpharm.2013.06.080

Fisher, M. B., and Mauck, R. L. (2013). Tissue engineering and regenerative medicine: recent innovations and the transition to translation. Tissue Eng. Part B Rev. 19, 1-13. doi:10.1089/ten.TEB.2012.0723

Fosgerau, K., and Hoffmann, T. (2015). Peptide therapeutics: current status and future directions. Drug Discov. Today 20, 122-128. doi:10.1016/j.drudis. 2014.10.003

\section{ACKNOWLEDGMENTS}

Authors thank Ms. Megan Livingston for helping with editing the text.

\section{FUNDING}

This work was supported by the Brown Foundation (Project ID, 18130011), the Hearst Foundation (Project ID, 18130017), by the Cullen Trust for Health Care Foundation (Project ID, 18130014) and by DoD USAMRMC (Project ID, W81XWH-15-1-0718).

Garner, B. C., Stoker, A. M., Kuroki, K., Evans, R., Cook, C. R., and Cook, J. L. (2011). Using animal models in osteoarthritis biomarker research. J. Knee Surg. 24, 251-264. doi:10.1055/s-0031-1297361

Gattazzo, F., Urciuolo, A., and Bonaldo, P. (2014). Extracellular matrix: a dynamic microenvironment for stem cell niche. Biochim. Biophys. 1840, 2506-2519. doi:10.1016/j.bbagen.2014.01.010

Geckil, H., Xu, F., Zhang, X., Moon, S., and Demirci, U. (2010). Engineering hydrogels as extracellular matrix mimics. Nanomedicine 5, 469-484. doi:10.2217/ nnm. 10.12

Gelain, F., Panseri, S., Antonini, S., Cunha, C., Donega, M., Lowery, J., et al. (2010). Transplantation of nanostructured composite scaffolds results in the regeneration of chronically injured spinal cords. ACS Nano 5, 227-236. doi:10.1021/ nn102461w

Gelain, F., Silva, D., Caprini, A., Taraballi, F., Natalello, A., Villa, O., et al. (2011). BMHP1-derived self-assembling peptides: hierarchically assembled structures with self-healing propensity and potential for tissue engineering applications. ACS Nano 5, 1845-1859. doi:10.1021/nn102663a

Guldberg, R. E. (2009). Spatiotemporal delivery strategies for promoting musculoskeletal tissue regeneration. J. Bone Miner. Res. 24, 1507-1511. doi:10.1359/ jbmr.090801

Harrison, R. H., St-Pierre, J.-P., and Stevens, M. M. (2014). Tissue engineering and regenerative medicine: a year in review. Tissue Eng. Part B Rev. 20, 1-16. doi:10.1089/ten.TEB.2013.0668

Henkel, J., Woodruff, M. A., Epari, D. R., Steck, R., Glatt, V., Dickinson, I. C., et al. (2013). Bone regeneration based on tissue engineering conceptions - a 21st century perspective. Bone Res. 1, 216. doi:10.4248/BR201303002

Hoffman, A. S. (2012). Hydrogels for biomedical applications. Adv. Drug Deliv. Rev. 64, 18-23. doi:10.1016/j.addr.2012.09.010

Hoffmann, J. C., and West, J. L. (2010). Three-dimensional photolithographic patterning of multiple bioactive ligands in poly (ethylene glycol) hydrogels. Soft Matter 6, 5056-5063. doi:10.1039/c0sm00140f

Horn, E. M., Beaumont, M., Shu, X. Z., Harvey, A., Prestwich, G. D., Horn, K. M., et al. (2007). Influence of cross-linked hyaluronic acid hydrogels on neurite outgrowth and recovery from spinal cord injury. J. Neurosurg. Spine 6, 133-140. doi:10.3171/spi.2007.6.2.133

Hosseinkhani, H., Hosseinkhani, M., Khademhosseini, A., Kobayashi, H., and Tabata, Y. (2006). Enhanced angiogenesis through controlled release of basic fibroblast growth factor from peptide amphiphile for tissue regeneration. Biomaterials 27, 5836-5844. doi:10.1016/j.biomaterials.2006.08.003

Hsu, W. K., Nickoli, M. S., Wang, J. C., Lieberman, J. R., An, H. S., Yoon, S. T., et al. (2012). Improving the clinical evidence of bone graft substitute technology in lumbar spine surgery. Global Spine J. 2, 239-248. doi:10.1055/s-00321315454

Humphrey, J. D., Dufresne, E. R., and Schwartz, M. A. (2014). Mechanotransduction and extracellular matrix homeostasis. Nat. Rev. Mol. Cell Biol. 15, 802-812. doi:10.1038/nrm3896

Ishii, O., Shin, M., Sueda, T., and Vacanti, J. P. (2005). In vitro tissue engineering of a cardiac graft using a degradable scaffold with an extracellular matrixlike topography. J. Thorac. Cardiovasc. Surg. 130, 1358-1363. doi:10.1016/j. jtcvs.2005.05.048

Jaklenec, A., Stamp, A., Deweerd, E., Sherwin, A., and Langer, R. (2012). Progress in the tissue engineering and stem cell industry "are we there yet?" Tissue Eng. Part B Rev. 18, 155-166. doi:10.1089/ten.teb.2011.0553 
Kaneko, H., Arakawa, T., Mano, H., Kaneda, T., Ogasawara, A., Nakagawa, M., et al. (2000). Direct stimulation of osteoclastic bone resorption by bone morphogenetic protein (BMP)-2 and expression of BMP receptors in mature osteoclasts. Bone 27, 479-486. doi:10.1016/S8756-3282(00)00358-6

Kim, K., Luu, Y. K., Chang, C., Fang, D., Hsiao, B. S., Chu, B., et al. (2004). Incorporation and controlled release of a hydrophilic antibiotic using poly (lactide-co-glycolide)-based electrospun nanofibrous scaffolds. J. Control. Release 98, 47-56. doi:10.1016/j.jconrel.2004.04.009

Kim, T. G., Shin, H., and Lim, D. W. (2012). Biomimetic scaffolds for tissue engineering. Adv. Funct. Mater. 22, 2446-2468. doi:10.1002/adfm.201103083

Lai, R.-F., Li, Z.-J., Zhou, Z.-Y., Feng, Z.-Q., and Zhao, Q.-T. (2013). Effect of rhBMP-2 sustained-release nanocapsules on the ectopic osteogenesis process in Sprague-Dawley rats. Asian Pac. J. Trop. Med. 6, 884-888. doi:10.1016/ s1995-7645(13)60157-1

Lee, M. K., Rich, M. H., Lee, J., and Kong, H. (2015a). A bio-inspired, microchanneled hydrogel with controlled spacing of cell adhesion ligands regulates 3D spatial organization of cells and tissue. Biomaterials 58, 26-34. doi:10.1016/j. biomaterials.2015.04.014

Lee, S. S., Hsu, E. L., Mendoza, M., Ghodasra, J., Nickoli, M. S., Ashtekar, A., et al. (2015b). Gel scaffolds of BMP-2-binding peptide amphiphile nanofibers for spinal arthrodesis. Adv. Healthc. Mater. 4, 131-141. doi:10.1002/adhm.201400129

Lee, T. T., García, J. R., Paez, J. I., Singh, A., Phelps, E. A., Weis, S., et al. (2015c). Light-triggered in vivo activation of adhesive peptides regulates cell adhesion, inflammation and vascularization of biomaterials. Nat. Mater. 14, 352-360. doi:10.1038/nmat4157

Li, N., and Folch, A. (2005). Integration of topographical and biochemical cues by axons during growth on microfabricated 3-D substrates. Exp. Cell Res. 311, 307-316. doi:10.1016/j.yexcr.2005.10.007

Liang, Y., and Kiick, K. L. (2014). Heparin-functionalized polymeric biomaterials in tissue engineering and drug delivery applications. Acta Biomater. 10, 1588-1600. doi:10.1016/j.actbio.2013.07.031

Lim, F., and Sun, A. M. (1980). Microencapsulated islets as bioartificial endocrine pancreas. Science 210, 908-910. doi:10.1126/science.6776628

Loh, Q. L., and Choong, C. (2013). Three-dimensional scaffolds for tissue engineering applications: role of porosity and pore size. Tissue Eng. Part B Rev. 19, 485-502. doi:10.1089/ten.TEB.2012.0437

López-Noriega, A., Quinlan, E., Celikkin, N., and O’Brien, F. J. (2015). Incorporation of polymeric microparticles into collagen-hydroxyapatite scaffolds for the delivery of a pro-osteogenic peptide for bone tissue engineering. APL Mater. 3, 014910. doi:10.1063/1.4902833

Lund, A. W., Yener, B., Stegemann, J. P., and Plopper, G. E. (2009). The natural and engineered $3 \mathrm{D}$ microenvironment as a regulatory cue during stem cell fate determination. Tissue Eng. Part B Rev. 15, 371-380. doi:10.1089/ten. TEB.2009.0270

Luo, Y., and Shoichet, M. S. (2004). A photolabile hydrogel for guided three-dimensional cell growth and migration. Nat. Mater. 3, 249-253. doi: $10.1038 /$ nmat 1092

Malik, R., Lelkes, P. I., and Cukierman, E. (2015). Biomechanical and biochemical remodeling of stromal extracellular matrix in cancer. Trends Biotechnol. 33, 230-236. doi:10.1016/j.tibtech.2015.01.004

McKay, W. F., Peckham, S. M., and Badura, J. M. (2007). A comprehensive clinical review of recombinant human bone morphogenetic protein-2 (INFUSE ${ }^{\circledR}$ Bone Graft). Int. Orthop. 31, 729-734. doi:10.1007/s00264-007-0418-6

McKie, J., Qureshi, S., Iatridis, J., Egorova, N., Cho, S., and Hecht, A. (2014). Trends in bone morphogenetic protein usage since the U.S. Food and Drug Administration Advisory in 2008: what happens to physician practices when the Food and Drug Administration issues an advisory? Global Spine J. 4, 71-76. doi:10.1055/s-0033-1363515

Minardi, S., Corradetti, B., Taraballi, F., Byun, J. H., Cabrera, F., Liu, X., et al. (2016). IL-4 release from a biomimetic scaffold for the temporally controlled modulation of macrophage response. Ann. Biomed. Eng. 1-12. doi:10.1007/ s10439-016-1580-z

Minardi, S., Corradetti, B., Taraballi, F., Sandri, M., Van Eps, J., Cabrera, F. J., et al. (2015). Evaluation of the osteoinductive potential of a bio-inspired scaffold mimicking the osteogenic niche for bone augmentation. Biomaterials 62, 128-137. doi:10.1016/j.biomaterials.2015.05.011S0142-9612(15)00461-5

Minardi, S., Sandri, M., Martinez, J. O., Yazdi, I. K., Liu, X., Ferrari, M., et al. (2014). Multiscale patterning of a biomimetic scaffold integrated with composite microspheres. Small 10, 3943-3953. doi:10.1002/smll.201401211
Mohan, N., Dormer, N. H., Caldwell, K. L., Key, V. H., Berkland, C. J., and Detamore, M. S. (2011). Continuous gradients of material composition and growth factors for effective regeneration of the osteochondral interface. Tissue Eng. Part A 17, 2845-2855. doi:10.1089/ten.tea.2011.0135

Nguyen, K. T., and West, J. L. (2002). Photopolymerizable hydrogels for tissue engineering applications. Biomaterials 23, 4307-4314. doi:10.1016/S01429612(02)00175-8

Pandolfi, L., Minardi, S., Taraballi, F., Liu, X., Ferrari, M., and Tasciotti, E. (2016). Composite microsphere-functionalized scaffold for the controlled release of small molecules in tissue engineering. J. Tissue Eng. 7, 2041731415624668. doi: $10.1177 / 2041731415624668$

Peppas, N. A., Hilt, J. Z., Khademhosseini, A., and Langer, R. (2006). Hydrogels in biology and medicine: from molecular principles to bionanotechnology. Adv. Mater. Weinheim 18, 1345-1360. doi:10.1002/adma.200501612

Place, E. S., Evans, N. D., and Stevens, M. M. (2009). Complexity in biomaterials for tissue engineering. Nat. Mater. 8, 457-470. doi:10.1038/nmat2441

Raghunathan, V., McKee, C., Cheung, W., Naik, R., Nealey, P. F., Russell, P., et al. (2013). Influence of extracellular matrix proteins and substratum topography on corneal epithelial cell alignment and migration. Tissue Eng. Part A 19, 1713-1722. doi:10.1089/ten.TEA.2012.0584

Rajangam, K., Arnold, M. S., Rocco, M. A., and Stupp, S. I. (2008). Peptide amphiphile nanostructure-heparin interactions and their relationship to bioactivity. Biomaterials 29, 3298-3305. doi:10.1016/j.biomaterials.2008.04.008

Robin, B. N., Chaput, C. D., Zeitouni, S., Rahm, M. D., Zerris, V. A., and Sampson, H. W. (2010). Cytokine-mediated inflammatory reaction following posterior cervical decompression and fusion associated with recombinant human bone morphogenetic protein-2: a case study. Spine 35, E1350. doi:10.1097/BRS.0b013e3181e85756

Santos, E., Hernández, R. M., Pedraz, J. L., and Orive, G. (2012). Novel advances in the design of three-dimensional bio-scaffolds to control cell fate: translation from 2D to 3D. Trends Biotechnol. 30, 331-341. doi:10.1016/j.tibtech.2012. 03.005

Seidi, A., Ramalingam, M., Elloumi-Hannachi, I., Ostrovidov, S., and Khademhosseini, A. (2011). Gradient biomaterials for soft-to-hard interface tissue engineering. Acta Biomater. 7, 1441-1451. doi:10.1016/j.actbio.2011. 01.011

Sheridan, C. (2010). Fresh from the biologic pipeline - 2009. Nat. Biotechnol. 28, 307-310. doi:10.1038/nbt0410-307

Shields, L. B. E., Raque, G. H., Glassman, S. D., Campbell, M., Vitaz, T., Harpring, J., et al. (2006). Adverse effects associated with high-dose recombinant human bone morphogenetic protein-2 use in anterior cervical spine fusion. Spine 31, 542-547. doi:10.1097/01.brs.0000201424.27509.72

Singh, M., Morris, C. P., Ellis, R. J., Detamore, M. S., and Berkland, C. (2008). Microsphere-based seamless scaffolds containing macroscopic gradients of encapsulated factors for tissue engineering. Tissue Eng. Part C Methods 14, 299-309. doi:10.1089/ten.tec.2008.0167

Smucker, J. D., Rhee, J. M., Singh, K., Yoon, S. T., and Heller, J. G. (2006). Increased swelling complications associated with off-label usage of rhBMP-2 in the anterior cervical spine. Spine 31,2813-2819. doi:10.1097/01.brs.0000245863. 52371.c2

Song, B., Wu, C., and Chang, J. (2012). Dual drug release from electrospun poly(lactic-co-glycolic acid)/mesoporous silica nanoparticles composite mats with distinct release profiles. Acta Biomater. 8, 1901-1907. doi:10.1016/j. actbio.2012.01.020

Sternlicht, M. D., and Werb, Z. (2001). How matrix metalloproteinases regulate cell behavior. Annu. Rev. Cell Dev. Biol. 17, 463. doi:10.1146/annurev.cellbio.17.1.463

Sun, Z., Zussman, E., Yarin, A. L., Wendorff, J. H., and Greiner, A. (2003). Compound core-shell polymer nanofibers by co-electrospinning. Adv. Mater Weinheim 15, 1929-1932. doi:10.1002/adma.200305136

Tampieri, A., Sandri, M., Landi, E., Pressato, D., Francioli, S., Quarto, R., et al. (2008). Design of graded biomimetic osteochondral composite scaffolds. Biomaterials 29, 3539-3546. doi:10.1016/j.biomaterials.2008.05.008

Tampieri, A., Sprio, S., Sandri, M., and Valentini, F. (2011). Mimicking natural bio-mineralization processes: a new tool for osteochondral scaffold development. Trends Biotechnol. 29, 526-535. doi:10.1016/j.tibtech.2011.04.011

Taraballi, F., Natalello, A., Campione, M., Villa, O., Doglia, S. M., Paleari, A., et al. (2010). Glycine-spacers influence functional motifs exposure and self-assembling propensity of functionalized substrates tailored for neural stem cell cultures. Front. Neuroeng. 3:1. doi:10.3389/neuro.16.001.2010 
Tian, H., Tang, Z., Zhuang, X., Chen, X., and Jing, X. (2012). Biodegradable synthetic polymers: preparation, functionalization and biomedical application. Prog. Polym. Sci. 37, 237-280. doi:10.1016/j.progpolymsci.2011.06.004

Tibbitt, M. W., and Anseth, K. S. (2009). Hydrogels as extracellular matrix mimics for 3D cell culture. Biotechnol. Bioeng. 103, 655-663. doi:10.1002/bit.22361

Transparency Market Research. (2012). Available at: http://www.transparencymar ketresearch.com/

Tsang, V. L., Chen, A. A., Cho, L. M., Jadin, K. D., Sah, R. L., DeLong, S., et al. (2007). Fabrication of 3D hepatic tissues by additive photopatterning of cellular hydrogels. FASEB J. 21, 790-801. doi:10.1096/fj.06-7117com

Ulrich, T. A., de Juan Pardo, E. M., and Kumar, S. (2009). The mechanical rigidity of the extracellular matrix regulates the structure, motility, and proliferation of glioma cells. Cancer Res. 69, 4167-4174. doi:10.1158/0008-5472. CAN-08-4859

Vo, T. N., Kasper, F. K., and Mikos, A. G. (2012). Strategies for controlled delivery of growth factors and cells for bone regeneration. Adv. Drug Deliv. Rev. 64, 1292-1309. doi:10.1016/j.addr.2012.01.016

Wang, E. A., Rosen, V., Cordes, P., Hewick, R. M., Kriz, M. J., Luxenberg, D. P., et al. (1988). Purification and characterization of other distinct bone-inducing factors. Proc. Natl. Acad. Sci. U.S.A. 85, 9484-9488. doi:10.1073/ pnas.85.24.9484

Wang, H., Zou, Q., Boerman, O. C., Nijhuis, A. W., Jansen, J. A., Li, Y., et al. (2013). Combined delivery of BMP-2 and bFGF from nanostructured colloidal gelatin gels and its effect on bone regeneration in vivo. J. Control. Release 166, 172-181. doi:10.1016/j.jconrel.2012.12.015

Wei, G., Jin, Q., Giannobile, W. V., and Ma, P. X. (2007). The enhancement of osteogenesis by nano-fibrous scaffolds incorporating rhBMP-7 nanospheres. Biomaterials 28, 2087-2096. doi:10.1016/j.biomaterials.2006.12.028

Wong, D. A., Kumar, A., Jatana, S., Ghiselli, G., and Wong, K. (2008). Neurologic impairment from ectopic bone in the lumbar canal: a potential complication of off-label PLIF/TLIF use of bone morphogenetic protein-2 (BMP-2). Spine J. 8, 1011-1018. doi:10.1016/j.spinee.2007.06.014

Yan, C., Sun, J., and Ding, J. (2011). Critical areas of cell adhesion on micropatterned surfaces. Biomaterials 32, 3931-3938. doi:10.1016/j.biomaterials.2011.01.078

Yañez-Soto, B., Liliensiek, S., Murphy, C., and Nealey, P. (2013). Biochemically and topographically engineered poly (ethylene glycol) diacrylate hydrogels with biomimetic characteristics as substrates for human corneal epithelial cells. J. Biomed. Mater. Res. A 101, 1184-1194. doi:10.1002/jbm.a.34412

Yuan, W., and Liu, Z. (2012). Controlled-release and preserved bioactivity of proteins from (self-assembled) core-shell double-walled microspheres. Int. J. Nanomed. 7, 257. doi:10.2147/IJN.S27621

Zara, J. N., Siu, R. K., Zhang, X., Shen, J., Ngo, R., Lee, M., et al. (2011). High doses of bone morphogenetic protein 2 induce structurally abnormal bone and inflammation in vivo. Tissue Eng. Part A 17, 1389-1399. doi:10.1089/ten. TEA.2010.0555

Zorlutuna, P., Jeong, J. H., Kong, H., and Bashir, R. (2011). Stereolithography-based hydrogel microenvironments to examine cellular interactions. Adv. Funct. Mater. 21, 3642-3651. doi:10.1002/adfm.201190080

Conflict of Interest Statement: The authors declare that the research was conducted in the absence of any commercial or financial relationships that could be construed as a potential conflict of interest.

Copyright (C) 2016 Minardi, Taraballi, Pandolfi and Tasciotti. This is an open-access article distributed under the terms of the Creative Commons Attribution License (CC BY). The use, distribution or reproduction in other forums is permitted, provided the original author (s) or licensor are credited and that the original publication in this journal is cited, in accordance with accepted academic practice. No use, distribution or reproduction is permitted which does not comply with these terms. 